\title{
Recent advance and future progress of GaN power semiconductor devices used in PV module integrated converters
}

*Óscar M. Rodríguez-Benítez, *Mario Ponce-Silva, ${ }^{+}$Leobardo Hernández González, **Juan A. Aquí-Tapia,

*Abraham Claudio Sánchez, *Gabriel Calzada Lara, *Claudia Cortés-García

* Tecnológico Nacional de México-CENIDET, 62490, Cuernavaca, Morelos, México

${ }^{+}$Instituto Politécnico Nacional, ESIME Culhuacán.

** Osram S.A. de C.V., Apodaca, Nuevo León, México

\begin{abstract}
Power semiconductor devices are essential from the operation point of view, size, efficiency and cost, these components are used in a myriad of applications, providing features that make them an important part of the system in which they are operating. This document analyzes and compares the basic structure, properties, design aspects, as well as temperature performance, stability and switching losses, present in devices on silicon $(\mathrm{Si})$, silicon carbide $(\mathrm{SiC})$ and new generation devices fabricated in gallium nitride $(\mathrm{GaN})$ applied in renewable energy systems. The main objective is determinate the viability of the new generation components, which present a superior performance in view of an increase in efficiency, conductivity, decreases in switching losses, lower resistances and parasitic capacitances as well as higher operating frequency range. Therefore demonstrating the $\mathrm{GaN}$ components are a strong and viable candidate to solve some of the problems present in renewable energy systems.
\end{abstract}

Keywords- Gallium nitride ( $\mathrm{GaN})$, silicon carbide ( $\mathrm{SiC})$, silicon ( $\mathrm{Si}$ ), converters, power devices, power electronics.

\section{INTRODUCTION}

Currently the increase of the efficiency in power semiconductor devices, is crucial for a better performance in a system or application. The material commonly used for the development of this type of devices is $\mathrm{Si}$, however, the physical properties of these components have certain limitations, which mean avoiding to think of this material as a firm candidate for the future of power electronics. Because of Si based devices are closer to their limits in terms of benefits, the study and effort, both academic and scientific has focused on finding alternatives to increase the performance of these components, through the use of new construction materials [1].

The growing interest in new semiconductor devices has led to a substantial development of electronic power devices, using $\mathrm{GaN}$ components as firm candidates for renewable energy systems allowing the increase of the electrical efficiency and high power density [2-5] due to the properties of the processing material, such as high current speed, higher bandgap and high dynamic response. On the other hand, the higher mobility and speed of its electron saturation, allows its operation at higher switching frequency. Part of these characteristics are presented in [6] and shown in Table 1, on the other hand, Table 2, shows the impact of GaN devices applied in conventional power amplifiers (PA) [7-9].

TABLE 1. Material properties of semiconductors

\begin{tabular}{|c|c|c|c|c|}
\hline Material & $\begin{array}{c}\text { Dielectric } \\
\text { Constant, } \boldsymbol{\varepsilon}\end{array}$ & $\begin{array}{c}\mathbf{T m a x}^{\circ} \mathbf{C} \\
\begin{array}{c}\text { Break } \\
\text { down } \\
\text { field, Eb } \\
\mathbf{1 0}^{\mathbf{6}} \mathbf{V} / \\
\mathbf{c m}\end{array}\end{array}$ & $\begin{array}{c}\text { Bangap, } \\
\text { Eg, eV }\end{array}$ \\
\hline $\mathrm{Si}$ & 11.9 & 300 & 0.3 & 1.12 \\
\hline $\mathrm{SiC}$ & 10 & 600 & 3.5 & 3.2 \\
\hline $\mathrm{GaN}$ & 9.5 & 700 & 2 & 3.4 \\
\hline
\end{tabular}

TABLE 2. Impact of GaN on PA concepts [6]

\begin{tabular}{|c|l|l|}
\hline Concept & \multicolumn{1}{|c|}{ Silicon } & \multicolumn{1}{|c|}{ GaN on SiC } \\
\hline Class E/F/J & $\begin{array}{l}\text { Low } f_{T}, \text { moderate } \\
\text { breakdown voltage }\end{array}$ & $\begin{array}{l}\text { High } f_{T}, \text { high } \\
\text { breakdown voltage }\end{array}$ \\
\hline Doherty & $\begin{array}{l}\text { Low off-state } \\
\text { impedance, high } \\
\text { output capacitance }\end{array}$ & $\begin{array}{l}\text { High off-state } \\
\text { impedance, low } \\
\text { output capacitance }\end{array}$ \\
\hline
\end{tabular}




\begin{tabular}{|c|l|l|}
\hline LINC & $\begin{array}{l}\text { Large non-linear } \\
\text { output capacitance }\end{array}$ & $\begin{array}{l}\text { Small non-linear } \\
\text { output capacitance }\end{array}$ \\
\hline EER/ET & $\begin{array}{l}\text { Poor amplitude to } \\
\text { phase modulation } \\
\text { conversion, moderate } \\
\text { bandwidth }\end{array}$ & $\begin{array}{l}\text { Good amplitude to } \\
\text { phase modulation } \\
\text { conversion, large } \\
\text { bandwidth }\end{array}$ \\
\hline
\end{tabular}

The main characteristics of the GaN devices lead to greater breakdown voltage and operating temperature [6], allowing to use higher drain voltage levels, obtaining lower energy losses.

Recent advances on GaN substrates, present better operating conditions than their predecessor technologies, attracting a renewed interest in the development of nitride devices [10,11], on the other hand, despite the fact that the cost of these components remains high and its availability relatively low, academic and scientific interest has increased over time, opening an area with great growth potential, accelerating progress in the development of various electronic and optoelectronic devices today.

This paper presents a review of the emerging emergence of new switching technologies based on GaN devices applied to power electronics and renewable energy systems. The main contribution of this paper, is to present the advantages and qualities of the GaN devices, according to a comparison an evaluation of these types of devices, in conventional and emerging technologies currently available.

This paper is organized as follows: Section II presents some antecedents and data from the composition of the nitride material, Section III presents the characteristics of the materials most commonly used nowadays, section IV shows the physical properties and main characteristics of the different devices analyzed, section $\mathrm{V}$ shows some applications in more recent photovoltaic systems reported in the literature, section VI presents some of the benefits gained due to the superior performance that the devices GaN present in front of other materials, finally in section VII concludes the current review mentioning the most outstanding points and characteristics.

\section{BACKGROUND AND DESCRIPTION}

The evolution of new construction materials for semiconductor power devices has progressed in recent years, leading to the use of devices made in nitride. The initial progress in $\mathrm{GaN}$ devices technology, started in the 1990s, focusing first on three important parameters [12]; the improvement of the quality of the material, the selection of the best materials of substrate and the development and innovation in the process of the elaboration and manufacture of new devices.

Some of first advances, were based on works of Metal-Organic Chemical Vapour Deposition (MOCVD) in the optoelectronic area, observing the feasibility of using electronic devices based on GaN [12-14], in this way part of these advances are they achieved first in sapphire due to their availability, to later opt for different materials in order to obtain superior properties of efficiency and performance [15-17].

Part of the advantages in the performance of GaN devices are highly notable due to their ability to "create" heterostructures in the same system, in addition of supporting high breakdown fields [18-20], due to their composition. Figure 1 shows the schematic cross section of their material, where the device is manufactured with ohmic contacts that are formed directly in the upper of the A1GaN structure.

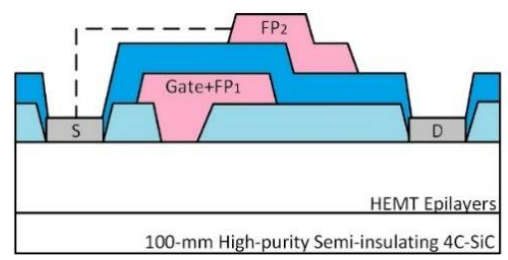

Fig. 1 Schematic cross section of the AlGaN/AlN/GaN structure

The isolation of the device is obtained using layers of nitrogen, to have a planar structure [21,22], on the other hand, the electrodes are formed from a dielectric, and finally the high electric fields take form at the side edge of the semiconductor junction of metal, which once optimized, includes a lateral extension to have a 
conformation with the gate metallization, which is used to compensate and reduce the resistance, the device's gate length is nominally of $0.4 \mu \mathrm{m}$ and the separation to drain is approximately $3 \mu \mathrm{m}$.

As part of optimization for this type of devices, a second board is included in the original design, to provide additional electric potential, which will form a high drain voltage to drain the feedback capacitance of the device [23-25].

The Gallium Nitride transistors (GaN) HEMT (High Electron Mobility transistor) has followed a remarkable evolution in its composition and fabrication, these devices appeared for the first time in 2004 as radio frequency transistors (RF), manufactured in Japan by Eudyna Corporation [26], which manufacture basically consisted of using $\mathrm{GaN}$ on $\mathrm{SiC}$ substrates. Its structure was based on the demonstration of unusually high electron mobility, described for the first time in 1975 by T. Mimura and in 1994 by M. A. Khan, describing this phenomenon as a two-dimensional electron gas (2DEG) near the interface between a heterostructure A1 GaN and GaN.

With the emergence of this phenomenon, the possibility of adapting it on gallium nitride was studied [26], cultivating on $\mathrm{SiC}$ and producing a reference power gain in the range of several gigahertz. Later in 2005, Nitroex corporation introduced the first HEMT RF transistor manufactured on $\mathrm{GaN}$ cultivated on $\mathrm{Si}$, using patented technology SIGANTIC®, finally in 2009, the first MOSFET's model developed on GaN was introduced by the Efficient Power Conversion Corporation.

Currently the basic requirements for any power semiconductor [27,28], are directly linked to efficiency, reliability, control, profitability and cost, the latter being the main current problem of new generation devices. In the following sections, a brief comparison between $\mathrm{Si}$, Sic and $\mathrm{GaN}$ devices is analyzed and mentioned in order to determinate the ideal candidate applied as switching device in power electronics. The comparison parameters considerate are driving efficiency, breakdown voltage, switching efficiency, size and cost.

\section{PHYSICAL PROPERTIES AND PERFORMANCE OF Si, SiC y GaN}

In an electronic power system there are key parameters that are important to know in order to elaborate an optimal design, some of these parameters or electrical magnitudes are given directly by the voltage, frequency, current or operating temperature, where according to these magnitudes, characteristics or utility of the system a certain application can be defined.

Part of the parameters necessary to carry out the experimental development of an electronic power system, is related to the appropriate choice of semiconductor devices. The choice of these devices depends on the application and operational characteristics that may have, in this sense Table 3 shown physical properties of $\mathrm{Si}$, $4 \mathrm{H}-\mathrm{SiC}$ and $\mathrm{GaN}$ devices that have been reported in the literature [29-31].

TABLE 3. Physical Properties of Silicon (Si), Silicon Carbide (4H-SiC) and Gallium Nitride GaN

\begin{tabular}{|c|c|c|c|c|}
\hline $\begin{array}{c}\text { Electrical } \\
\text { Property }\end{array}$ & Uni. & $\mathbf{S i}$ & $\mathbf{4 H - S i C}$ & $\mathbf{G a N}$ \\
\hline $\begin{array}{c}\text { Band Gap } \\
\text { Energy }\end{array}$ & $\mathrm{eV}$ & 1.1 & 3.26 & 3.4 \\
\hline $\begin{array}{c}\text { Thermal } \\
\text { Conduction }\end{array}$ & $\mathrm{W} / \mathrm{cm} . \mathrm{K}$ & 1.5 & 3.7 & 1.3 \\
\hline $\begin{array}{c}\text { Electron } \\
\text { Mobility }\end{array}$ & $\mathrm{cm}^{2} / \mathrm{V} . \mathrm{s}$ & 1300 & 900 & $900-2000$ \\
\hline $\begin{array}{c}\text { Saturation } \\
\text { Drift } \\
\text { Velocity }\end{array}$ & $\mathrm{cm} / \mathrm{s}$ & $1 \times 10^{7}$ & $2 \times 10^{7}$ & $2.5 \times 10^{7}$ \\
\hline
\end{tabular}

Table 3 shows that the semiconductors made with $\mathrm{SiC}$ and $\mathrm{GaN}$ present a higher wide-bandgap than semiconductors made in $\mathrm{Si}$, this fact results in more efficient and resistant components to applications of higher temperature ranges, due to the fact that $\mathrm{SiC}$ and $\mathrm{GaN}$ as the temperature increases the thermal energy of the electrons in their balance band increases, avoiding uncontrolled energy conductions that occur at a temperature of around $150^{\circ} \mathrm{C}$ [32], increasing their efficiency and quality of operation. 
Another important feature in devices made on $\mathrm{GaN}$, is the fact that they are thinner power devices than their counterparts based on $\mathrm{Si}$ and $\mathrm{SiC}$. In addition to present lower resistance $\left(\mathrm{R}_{\mathrm{ON}}\right)$. Some comparisons between different materials are reported in [33] regarding this point, of which the comparison among the 3 materials mentioned above is presented in Fig. 2.

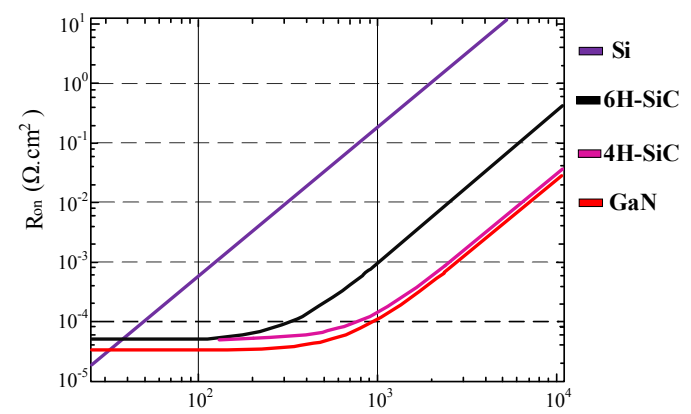

Fig. 2 On-State Resistance vs Breakdown Voltage

The capacity that every semiconductor device presents to achieve high switching frequency is directly proportional to its saturation drift velocity, the speed presents in $\mathrm{GaN}$ devices is more than twice the speed in components made of Si $\left(1 X 10^{7}\right)$, achieving commutations at much higher frequencies, which improves aspects related to efficiency for certain applications, decreasing some of the most common problems presented by robust elements such as inductors or transformers, due to the higher frequency of operation, it is possible to decrease the construction size of the same, giving smaller elements and therefore with lower power losses due to the core [34-36].

Another important part in this type of devices is related to the displacement speed, allowing an almost nonexistent reverse recovery present in devices made of silicon [37,38].

On the other hand, a negative part that the $\mathrm{GaN}$ devices presents in comparison with $\mathrm{Si}$ and $\mathrm{SiC}$ devices, is a lower thermal conductivity [39-41], which means that heat generation of SiC devices can be easily dissipated than in one made development of GaN. An analysis more thorough and detailed of the physical properties of these three materials, is shown in Fig. 3.

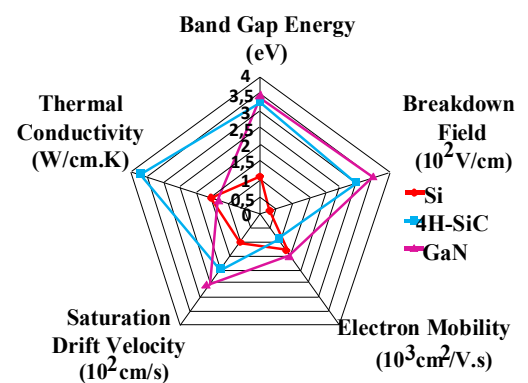

Fig. 3 Comparison between $\mathrm{Si}, 4 \mathrm{H}-\mathrm{SiC}$ and $\mathrm{GaN}$

From the analysis presented in Fig. 3, it can be concluded that the power devices of GaN are a good choice for applications in high switching frequency and high voltage levels, however the devices manufactured of SiC have qualities very similar to those of $\mathrm{GaN}$, currently positioning them as a strong candidate for a lot applications, due to its lower cost and easy access. On the other hand, the recent emergence of devices developed in $\mathrm{GaN}$ provides for a wide margin of improvement, which could be positioned as the most complete device for a host of applications, even over the devices developed of $\mathrm{SiC}$ [42].

The next section shown the main questions that are presented in new generation devices, as well as a series of comparisons and inflection points, which position the semiconductor devices of $\mathrm{GaN}$ as a good choice of present and better alternative to the future, in comparison with devices made of silicon. 


\section{QUESTIONS AND ADVANTAGES}

GaN power semiconductor devices have been designed for an efficient and reliable energy conversion [43-45], unfortunately, nowadays it is a technology that does not have much more significant attention from the academic and scientific areas. Due to certain factors that keep them somewhat in the shadow of the devices elaborated of $\mathrm{Si}$ [46], but especially from devices elaborated on $\mathrm{SiC}$ [47], part of these problems is related, with four fundamental points, same that are presented in [48] and are briefly mentioned below.

\subsection{Product accessibility}

The first point is related to the risk of supply or difficult access to devices, this point is not entirely true, because the list of companies that sell GaN devices is growing almost every month, companies as; Efficient Power Conversion Corp., GaN Systems, Dialog Semiconductor, Navitas Semiconductor, Panasonic, Transphorm, Texas Instruments, ON Semiconductor, Sanken among others, they represent the possibility of acquiring a detailed series of devices made on $\mathrm{GaN}$, in this way, it is difficult to believe that with the support of such companies there is a real risk of supply.

\subsection{Cost}

The aspect related to cost is an interesting point to analyze [49-51], because the devices of GaN lead to greater investment than its counterpart in $\mathrm{Si}$, due to the fact that they are relatively recent technologies, at this point you will have much to see if the investment is necessary depending on the application, on the other hand from a broader point of view, the higher cost not only leads to the purchase of a new device generation, but also all the features that it presents, which as shown in section VI of this document, are better than in other cheaper devices, so depending on the perspective that is given, results in a justifiable investment. A clear example is shown in Table 4, where a comparison of costs between GaN and Si MOSFETs, under the same voltage levels, and ignition resistance is shown, so the cost reduction by the components of GaN mark a decreasing trend over the years.

TABLE 4. Comparison of GaN transistor costs and silicon MOSFETs with the same voltage and ON-

Resistance [48]

\begin{tabular}{|c|c|c|}
\multicolumn{2}{|c|}{ Resistance $[48]$} \\
\hline Starting material & $\mathbf{2 0 1 0}$ & $\mathbf{2 0 1 5}$ \\
\hline Epi Growth & Higher & Same \\
\hline Wafer Fab & Same & Same \\
\hline Test & Same & Same \\
\hline Assembly & Lower & Lower \\
\hline Overall & Higher & Lower \\
\hline
\end{tabular}

\subsection{Reliability}

The criterion focused on the reliability of some devices is fundamental because in any power electronic system, this parameter is vital for any application $[52,53]$, in this sense there has been a huge amount of evidence related to the appearance of reliability, on devices of GaN by EPC, GaN Systems, Panasonic and Transphorm, which have determined that the devices $\mathrm{GaN}$ exceeded in an outstanding manner the tests carried out [54], whose standards are originally designed for testing $\mathrm{SiC}$ devices, which conditions a little this aspect, because it is still questioned if these tests are suitable mainly for components of GaN, due to the completely different material. On the other hand, despite the fact that there is still much to be learned about the failure mechanisms related to technologies of $\mathrm{GaN}$, there is supporting evidence that suggests excellent reliability of these devices, some of these records are presented in Figure 4, where reliability results are shown after 6 years of operation, demonstrating that $\mathrm{GaN}$ it has better characteristics than components made in silicon [55].

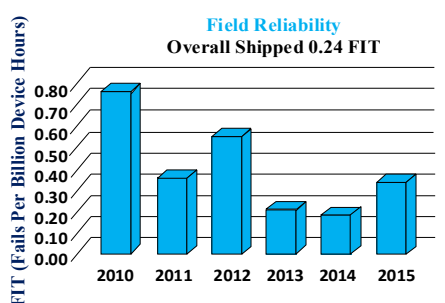

Fig. 4 GaN FET reliability over 6 years and 17 billion hours in the field [48] 


\subsection{Complexity in use}

Use of GaN devices is quite similar in behavior with the use of conventional MOSFETs (except for its superior performance), on the other hand, there are points to have in consideration, and such is the case to have special attention in the manipulation of component, due to its small size [56], therefore, they require more strict assembly tolerances. Nowadays the PCB circuit manufacturing technology, is improving, being able to find manufacturers that meet and exceed the capabilities necessary for an optimal performance.

According to the main questions in the use of new generation devices, many works reported in the literature have detailed throughout the last 5 years, interesting aspects as proposal to a solution of the problems related to low efficiencies, especially triggered by switching losses in converters, problems associated with amplifiers, applications based on current inverters, etc., Therefore, the GaN devices are presented as a candidate firm to give solution to them, due to its unique characteristics of operation.

Some of the main features and benefits of GaN devices have reported in the literature [57-64], are reviewed and mentioned below:

1. GaN devices present greater efficiency and power density, in addition, they are considerably smaller than their competitors made of $\mathrm{Si}$ and $\mathrm{SiC}$.

2. GaN devices present lower power losses due to the high mobility of the carriers in the two-dimensional electron gas channel, so they do not have an inverse recovery charge.

3. GaN technologies are ideal for working in high frequency power electronic systems (between $200 \mathrm{kHz}$ and $1 \mathrm{MHz})$

4. They have less on-state resistance than any other devices made in $\mathrm{Si}$ or SiC.

5. They have much faster commutations, reducing switching losses.

6. The devices manufactured of $\mathrm{SiC}$ have an intrinsic diode, which in idle time remains active, causing power losses in the diode, associated with its voltage, $\mathrm{GaN}$ devices on the other hand, have a higher driving voltage in the third quadrant, this also means that there are losses during the dead time, but it is much smaller, guaranteeing smaller losses.

7. The devices manufactured on GaN, have lower parasitic capacitances, due to the same ignition resistance compared to any other device.

Each of the points mentioned above represent interesting facts and characteristics to explore, which suggest a generational change in the material construction of different types of components between $\mathrm{SiC}$ and $\mathrm{GaN}$ in the near future. These operation characteristics of operation have been achieved due to a marked progress of semiconductors in power electronics, for a host of applications, for this reason, some of the main works that present these characteristics are briefly detailed in the following section.

\section{APPLICATIONS IN PV SYSTEMS}

GaN power semiconductors are devices that have a high thermic conductivity and higher switching speed than conventional components fabricated of Si [65], and even those made of SiC. The advance of the GaN devices, offers greater advantages in the performance in power converters, because their switches are much more efficient than any other device today.

On the other hand, the use of this type of components is ideal in applications that require operator under frequency levels in the order of $\mathrm{MHz}$, significantly reducing the size of passive components. Currently, the use of GaN devices in power converters is still at an early stage of development, but its widespread application is a close reality.

One of the areas of more development in recent years and which could benefit more from the use of GaN semiconductors are the systems of electric power generation through photovoltaic systems, because thanks to the features of these components, this type of systems would be benefit greatly from the point of view of efficiency and reliability.

Below are some works focused on the use of GaN devices in photovoltaic systems are presented the results demonstrate that $\mathrm{GaN}$ devices surpass the best $\mathrm{Si}$ devices and are broadly competent against front $\mathrm{SiC}$ devices technologies. 
The performance that GaN devices present in comparison with conventional technologies in semiconductors, has already been reported in the literature in previous years, through its use in DC-DC converters, works on it through analysis in a boost converter were presented [66-70], as well as studies focused on dual active bridge converter [71].

PV system applications, specifically on DC-DC converters, could greatly benefit from GaN technology, these converters could have an increase of efficiency and performance, as well as a reduction of losses, derived from the switching of their switches.

Unfortunately, in conventional photovoltaic systems, not only a higher efficiency in the DC-DC converter is sought, but also other aspects related to the efficient extraction of energy by the solar cells, due to this a large part of the effort devoted by the academic and scientific area for this type of applications, is focused on finding solutions to aspects related to environmental conditions, orientation of the module, shading, dirt, misalignment, monitoring of the maximum power point tracking (MPPT), increase in reliability among some others [72-81].

In recent years the optimization and evolution of photovoltaic systems have increased, nowadays the companies or sectors related to this application offer more optimized power converters. The increase in performance of commonly used DC-DC converters should be optimally designed according to the requirements of the system. The available solutions reported in the literature to increase the efficiency and improve the problems associated with this power stage for photovoltaic systems proposes optimized solutions for the converters that are used every year, but which they are regularly viewed under the same evaluation criteria.

Applications based on photovoltaic systems, have 3 specifications in the design of DC-DC converters [82], which from the point of view to the use of new technologies in semiconductors, can be addressed, these aspects are related to the electrical, thermal and technological part, same as mentioned briefly below.

\section{a. Electric specifications.}

The main aspect of an electric design, is the performance requirements of the PV system, with the objective to have the lowest number of losses of energy in the operation of the system, this is related directly with the size of the final prototype, relating in turn to use of the switching frequency, this parameter is very important because at lower switching frequency, the requirements for the thermic design can vary, while an increment of the switching frequency, leads to the decrease of the passive components that are in the system, so the use of GaN components, represents the advantage of operates in the order of $\mathrm{MHz}$. Therefore, for any topology with this conjecture, the switching frequency represents the main equilibrium parameter, between the power density of the system and the behavior of the temperature.

\section{b. Thermic specifications.}

Thermic specifications are related with the temperature of the photovoltaic panel, because the panel can easily reach $70{ }^{\circ} \mathrm{C}$ with it operation of more. On the same way not only the panel suffers of this excessive heating, another stage of the system with the same problem is the DC-DC converter, because part of the heat due to power losses are directly related to their components, which when operating at elevated temperatures, they see more diminished their useful life, compromising the operation of the system. In this case from the point of view of semiconductor devices one proposal is the use of new generation devices, which together with an optimized thermic design can help to decrease high temperatures reached in DC-DC converter.

\section{c. Technological requirements.}

Technological requirements for a good performance are related to efficiency, performance, reliability and volume that design presents considering these parameters, in addition the use of materials that help to satisfy these aspects as much as possible. From the aforementioned parameters, use of GaN devices could have benefits related to the efficiency and reduction in the final size of the required converter, obtaining stages with a reduced final volume, helping not only in aspects related to size, but also in aspects relate to reliability, because they have better performance, than semiconductor devices fabricated on $\mathrm{Si}$ and $\mathrm{SiC}$.

One work focused on the comparison between $\mathrm{GaN}$ and $\mathrm{SiC}$ semiconductor devices is presented in [83], by a topology designed with a QZS-CMI (Quasi Z-Source Cascaded Multilevel Module) for a power output of 1 
MW, the work proposes two possible solutions, the first one through the use of GaN devices and the second one through the use of $\mathrm{SiC}$ devices, the topology proposed, is shown in Figure 5.

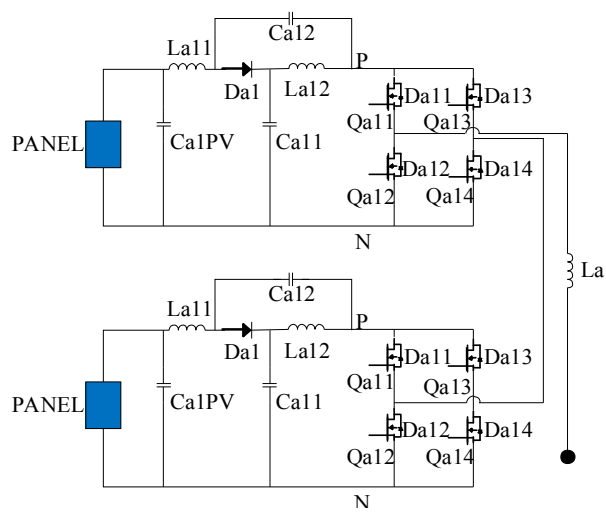

Fig. 5 Topology for $1 \mathrm{MW} / 11 \mathrm{kV}$ QZS-CMI

Topology on Figure 5 presents two alternative solutions for a photovoltaic application through the use of GaN and $\mathrm{SiC}$ devices, the presented work shows the performance of both materials and the benefits that they offer in this application, and how they help to increase or reduce the electrical properties in the system.

The possible solutions propose the following components: the first one proposes the use of a GaN device of $650 \mathrm{~V}$, model E-HEMT GS66516T of GaN Systems like switch, and a diode of SiC of $650 \mathrm{~V}$ model C5D50065D of Cree operating at $20 \mathrm{kHz}$, on the other hand, the second option proposes the use of a $\mathrm{SiC}$ component of $1200 \mathrm{~V}$ model CAS120M12BM2 of Cree operating at $10 \mathrm{kHz}$, the components used in both solutions are shown in Table 5.

TABLE 5. Components of both solutions

\begin{tabular}{|c|c|}
\hline First Solution & Second Solution \\
\hline Components & Components \\
\hline GaN E-HEMT & SiC half-bridge module \\
\hline Gate Driver & Gate Driver \\
\hline SiC Schottky diode & SiC Schottky diode \\
\hline qZS inductor & qZS inductor \\
\hline qZS capacitor & qZS capacitor \\
\hline Output filter inductor & Output filter inductor \\
\hline Output filter capacitor & Output filter capacitor \\
\hline PV terminal capacitor & PV terminal capacitor \\
\hline
\end{tabular}

The first solution according to the switch model chosen in $\mathrm{GaN}$ requires two components with anti-parallel diodes to satisfy the current requirement, with a margin of $44 \%$, the second one presents a current margin in the $\mathrm{SiC}$ module of approximately one $62 \%$, the negative element visible in the proposed topology from the use of $\mathrm{GaN}$ components is reflected in the need to use a greater number of components, in order to satisfy the operational requirements of the selected topology, on the other hand, part of the benefits that the use of GaN components entails consists of having lower ignition resistances and less parasitic capacitance.

An exhaustive analysis is presented in [83] obtaining the total losses in one and another solution, based on the operating principle of the proposed topology. As a summary, Figure 6 shown the distribution of losses in both cases operating with a frequency of $20 \mathrm{kHz}$, noting that despite having a greater number of components in the option using $\mathrm{GaN}$ better benefits are obtained from the point of view of efficiency. 


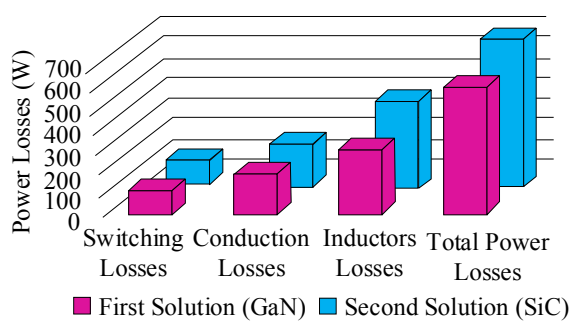

Fig. 6 Comparisons of power losses between $\mathrm{GaN}$ and $\mathrm{SiC}$

Figure 6 shown both options operating at a frequency of $20 \mathrm{kHz}$, concluding that although the switching losses in the first solution is twice than the second, the first solution still shows power losses in each module, but given the better switching characteristics in GaN power devices, switching losses are much lower than in the second option using $\mathrm{SiC}$ semiconductor components.

The power losses on the semiconductor devices is improved by $13.6 \%$ through the use of GaN semiconductors, therefore in terms of energy management and efficiency of the switching stages, the GaN semiconductors are superior than $\mathrm{SiC}$ devices. Another important aspect to take into account in the choice of any power device is the economic part, this point results in a negative aspect of the use of GaN components, the article similarly performs this exercise, obtaining that under a scheme using $\mathrm{GaN}$ devices the investment is $\$ 93,825$ and under a scheme using $\mathrm{SiC}$ devices, the investment is $\$ 65,940$ (price in dollars).

In the aspect related to costs, it is concluded that the price per module, for the solution through $\mathrm{GaN}$ is $31.18 \%$ less than that presented by $\mathrm{SiC}$, however, the total cost of the solution system in $\mathrm{GaN}$ is much higher than the solution in $\mathrm{SiC}$, due to the greater number of components necessary to satisfy the operating parameters.

Another work focused on evaluating the use of $\mathrm{GaN}$ semiconductor components in photovoltaic applications, is the one shown in [84], presenting a performance comparison in a DC-DC converter using GaN and $\mathrm{Si}$ components for an output power of $117 \mathrm{~W}$, noting that gallium devices outperform the best components based on $\mathrm{Si}$, the topology and the system used are shown in the following figure.
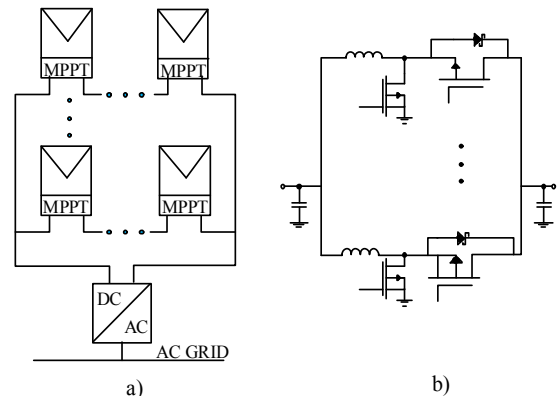

b)

Fig. 7 (a) System, (b) Converter topology

The comparative study was developed with the objective to observe the performance and operation that converter presents, due to the effect of "on resistance" and "parasitic capacitance". The characteristics of the components used are presented in Table 6.

TABLE 6. Device Selection

\begin{tabular}{|c|c|c|c|c|}
\hline Device & Model & $\boldsymbol{V}_{\boldsymbol{D S S}}$ & $\boldsymbol{R}_{\boldsymbol{D S}(\boldsymbol{O} \boldsymbol{N})}$ & $\boldsymbol{I}_{\boldsymbol{D}}$ \\
\hline $\mathrm{GaN}$ & EPC2001 & $100 \mathrm{~V}$ & $7 \mathrm{~m} \boldsymbol{\Omega}$ & $25 \mathrm{~A}$ \\
\hline $\mathrm{Si}$ & $\mathrm{IPB} 26 \mathrm{CN} 10$ & $100 \mathrm{~V}$ & $25 \mathrm{~m} \boldsymbol{\Omega}$ & $35 \mathrm{~A}$ \\
\hline
\end{tabular}

The obtained results by using GaN devices present better performance in terms of efficiency in the complete system, observing that due to the increase of the switching frequency, the value of the passive components are reduced, the adjustment and the components used in the design are shown in Table 7. 
TABLE 7. Specifications of used components

\begin{tabular}{|c|c|c|c|c|}
\hline Parameter & $\begin{array}{c}\boldsymbol{f}_{\text {sw }} \\
\mathbf{H z}\end{array}$ & $\begin{array}{c}\mathbf{L} \\
{[\boldsymbol{\mu H}]}\end{array}$ & $\begin{array}{c}\boldsymbol{C}_{\boldsymbol{i n}} \\
{[\boldsymbol{\mu} \boldsymbol{F}]}\end{array}$ & $\begin{array}{c}\boldsymbol{C}_{\text {out }} \\
{[\boldsymbol{\mu} \boldsymbol{F}]}\end{array}$ \\
\hline $\begin{array}{c}\mathrm{Si} \\
\text { Converter }\end{array}$ & 300 & 8.3 & 2.8 & 5.7 \\
\hline $\begin{array}{c}\mathrm{GaN} \\
\text { Converter }\end{array}$ & 600 & 4.2 & 1.5 & 3 \\
\hline
\end{tabular}

Finally, the distribution of the switching losses in comparison with the operating characteristics of the components used is presented, in Figure 8, in which a better performance is presented by the GaN devices.

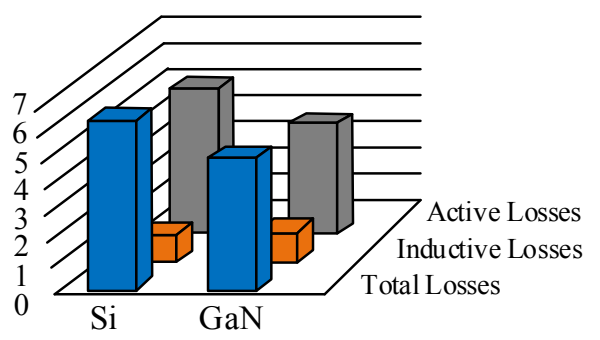

Fig. 8 Converter Losses

Due to the superior switching characteristics, the widespread use of the GaN components in power electronics is a closer reality, part of the improvements in switching would improve the most efficient energy conversion, while allowing a switching frequency greater that helps decrease the final volume of the system. In this aspect, from the point of view of photovoltaic systems, aspects related to efficiency, reliability and volume would be improved, they are fundamental aspects at present, because represent important requirements in their constitution of this type of applications.

The previous works shown only some of the comparisons that have been reported in the literature under conventional schemes in photovoltaic systems, up to this point it has been mentioned that one of the main advantages that involves the use of GaN components is related to increase the switching frequency, decreasing the size of the passive components such as inductors and therefore an increase of power density.

Currently there is a small number of works [85-92] related the use of current source inverters CSI for photovoltaic systems, which according to their authors, have interesting characteristics compared to the use of voltage inverters VSI, more employees for this type of topology.

However, part of the main problems associated with the use of CSI in photovoltaic systems are related to low efficiency, because they use bulky components that make them prone to present losses due to their design, right here it is important to mention part of the advantages that would bring the use of GaN power semiconductors in this type of schemes for photovoltaic systems, due to the advantage of being able to operate under much higher frequency levels than in any other device.

A related work in this aspect, is presented in [36], it proposes a topology and control scheme with an energy decoupling circuit for single-phase applications based on a current inverter, the proposed scheme complies with the electric norms stipulated for this type of applications, avoids the use of electrolytic capacitors and emerges as an interesting option to the problem of the reliability present in this type of systems.

The proposed inverter is shown in Figure 9 and consists of a switch, two diodes and a small capacitor, so the size and the number of components are reduced in comparison with the conventional circuits. 


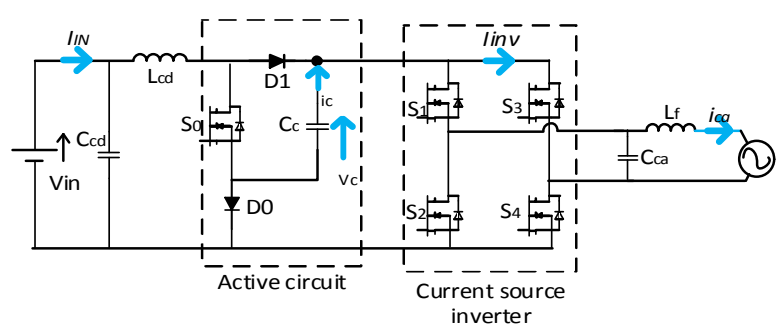

Fig. 9 Photovoltaic inverter presented in [36]

The inverter shown in Figure 9 decouples the energy through a small film capacitor, in this sense, is the same inverter that can control the DC input voltage and achieve the MPPT, providing a sinusoidal current to the grid with a less number of components.

The results obtained by Yoshiya Uhnuma present interesting characteristics of efficiency and power factor with respect to the output power, where is observed a maximum efficiency of $94.9 \%$, these results are compared with conventional topologies using a VSI, which are presented in Figure 10.

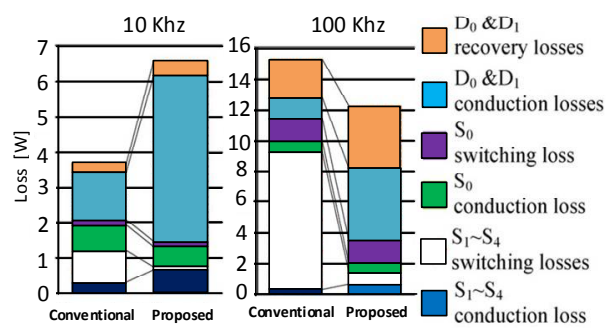

Fig. 10 Comparison of losses at different operating frequencies

Figure 10 shows the losses distribution present in a conventional topology (VSI) and the proposed scheme (CSI), it is observed that when the switching frequency is about $10 \mathrm{kHz}$, in the proposed circuit the conduction losses of the diodes is higher, on the other hand by increasing the switching frequency, the losses are lower using CSI, achieving important results, but that is still somewhat below the efficiencies presented by the most of the VSI currently, where estimated efficiencies are superior than $97 \%$.

Under these types of topologies and from the point of view of new generation components developed on GaN, they could increase the benefits of the use of CSI in photovoltaic systems, because part of the main problems associated with these investors are linked to problems of efficiency in the switches and the great bulk in its passive components, which can be benefited or improved only by the replacement of semiconductor components.

In summary, based on the analysis of energy losses between the components of GaN and $\mathrm{SiC}$, it is concluded that although the first solution shows lower power losses, there is a substantial increase in the final cost of the system when using GaN, same that conditions a wider use of this emergent technology at the present time, on the other hand, given the promising innovations in the GaN devices, it is totally possible to expect that the price of components elaborated in $\mathrm{GaN}$ diminish in the near future, existing a possible generational change reality in the use of the material for the mass manufacture of semiconductor devices, which is currently led, at the moment by components based on $\mathrm{SiC}$.

\section{CONCLUSIONS}

There are many advantages that lead to the use of power semiconductor devices based on GaN, part of them highlights the increase in the efficiency of any system compared to Si and SiC devices, the data show, for example, a reduction in noise for the use in robust amplifiers, eliminating the need for limiters of a diode as protection against overexertion, additionally, due to its physical characteristics and its high mobility of electrons, it grants special properties for applications in high power and frequency. 
The sensitivity of ionizing radiation for this type of devices is the lowest that any other device currently, so not only complies as a component for "normal" applications, but also for military and space applications due to its stability in environments of radiation, have lower ignition resistances, lower parasite capacitances, do not present inverse recovery time, help in the reduction of conduction losses and switching in converters, help to reduce robust components thanks to the fact that they operate in high frequency, in addition to a series of aspects that in comparison with $\mathrm{Si}$ and $\mathrm{SiC}$ devices make them more profitable.

Another important point that the GaN devices are presenting in front of any other device currently is the fact of having a higher reliability, helping applications that require a long lifetime, such is the case of power LED systems or photovoltaic systems, which need components with high reliability.

On the other hand, aspects related to its cost and the fact of operating at lower temperatures than SiC devices, positions them a bit below currently as leading components in applications related to power electronics. The positive part of this, as a recent technology there is still much room for improvement, this suggests that the components developed in $\mathrm{GaN}$ can be the super component that helps mitigate many of the problems associated with switches in power electronics, in this sense it is well known that many companies, distributors, designers and researchers are in various stages of adoption towards this new technology in semiconductors, while there is another more conservative sector that expects to find more compelling reasons to bet on them.

With a view to the near future, the devices developed in GaN will have a decrease in their price, which will help to better see the performance and advantages they have over the current power devices. So this may be translated as a generational change of components in applications where $\mathrm{Si}$ and $\mathrm{SiC}$ devices are commonly used, making current applications faster, more efficient, more reliable, smaller and with higher energy density.

\section{REFERENCES}

1. Waffenschmidt, E.; Ackermann, B.; Ferreira, J.A. Design method and material technologies for passives in printed circuit board embedded circuits. IEEE Transactions on Power Electronics 2005, 20, 576-584.

2. Ho, C.N.-M.; Breuninger, H.; Pettersson, S.; Escobar, G.; Canales, F. A comparative performance study of an interleaved boost converter using commercial $\mathrm{Si}$ and $\mathrm{SiC}$ diodes for PV applications. IEEE Transactions on Power Electronics 2013, 28, 289299.

3. Kim, T.; Jang, M.; Agelidis, V.G. Practical implementation of a silicon carbide-based $300 \mathrm{kHz}, 1.2 \mathrm{~kW}$ hard-switching boostconverter and comparative thermal performance evaluation. IET Power Electronics 2014, 8, 333-341.

4. Gurpinar, E.; Iannuzzo, F.; Yang, Y.; Castellazzi, A.; Blaabjerg, F. Design of Low Inductance Switching Power Cell for GaN HEMT Based Inverter. IEEE Transactions on Industry Applications 2017.

5. Samir, A.; Taha, M.; Sayed, M.M.; Ibrahim, A. Efficient PV-grid system integration with PV-voltage-source converter reactive power support. The Journal of Engineering 2018, 2018, 130-137.

6. Pengelly, R.S.; Wood, S.M.; Milligan, J.W.; Sheppard, S.T.; Pribble, W.L. A review of GaN on SiC high electron-mobility power transistors and MMICs. IEEE Transactions on Microwave Theory and Techniques 2012, 60, 1764-1783.

7. McGrath, S.; Rodle, T. Moving past the hype: Real opportunities for wide bandgap compound semiconductors in RF power markets. CSMantech On-Line Dig 2005.

8. Enomoto, J.; Ishikawa, R.; Honjo, K. Second Harmonic Treatment Technique for Bandwidth Enhancement of GaN HEMT Amplifier With Harmonic Reactive Terminations. IEEE Transactions on Microwave Theory and Techniques 2017, 65, 49474952 .

9. $\quad$ Lee, H.; Lim, W.; Bae, J.; Lee, W.; Kang, H.; Hwang, K.C.; Lee, K.-Y.; Park, C.-S.; Yang, Y. Highly Efficient Fully Integrated GaN-HEMT Doherty Power Amplifier Based on Compact Load Network. IEEE Transactions on Microwave Theory and Techniques 2017, 65, 5203-5211.

10. Halder, S.; Kharabi, F.; Howle, T.; McMacken, J.; Burns, C.; Le Fevre, M.; Runton, D.; Gering, J. Broadband lumped package modeling for scaling multi-cell GaN HEMT power devices. In Proceedings of Microwave Measurement Conference (ARFTG), 2012 79th ARFTG; pp. 1-3.

11. Ayad, M.; Byk, E.; Neveux, G.; Camiade, M.; Barataud, D. Single and dual input packaged 5.5-6.5 GHz, 20W, Quasi-MMIC GaN-HEMT Doherty Power Amplifier. In Proceedings of Microwave Symposium (IMS), 2017 IEEE MTT-S International; pp. 114-117.

12. Gaska, R.; Yang, J.; Osinsky, A.; Chen, Q.; Khan, M.A.; Orlov, A.; Snider, G.; Shur, M. Electron transport in AlGaN-GaN heterostructures grown on $6 \mathrm{H}-\mathrm{SiC}$ substrates. applied physics letters 1998, 72, 707-709.

13. Keller, S.; Parish, G.; Fini, P.; Heikman, S.; Chen, C.-H.; Zhang, N.; DenBaars, S.; Mishra, U.; Wu, Y.-F. Metalorganic chemical vapor deposition of high mobility AlGaN/GaN heterostructures. Journal of applied physics 1999, 86, 5850-5857.

14. Smorchkova, I.; Elsass, C.; Ibbetson, J.; Vetury, R.; Heying, B.; Fini, P.; Haus, E.; DenBaars, S.; Speck, J.; Mishra, U. Polarization-induced charge and electron mobility in AlGaN/GaN heterostructures grown by plasma-assisted molecular-beam epitaxy. Journal of applied physics 1999, 86, 4520-4526.

15. Green, B.M.; Chu, K.K.; Chumbes, E.M.; Smart, J.A.; Shealy, J.R.; Eastman, L.F. The effect of surface passivation on the microwave characteristics of undoped AlGaN/GaN HEMTs. IEEE Electron Device Letters 2000, 21, 268-270.

16. Wu, Y.-F.; Kapolnek, D.; Ibbetson, J.P.; Parikh, P.; Keller, B.P.; Mishra, U.K. Very-high power density AlGaN/GaN HEMTs. IEEE Transactions on Electron Devices 2001, 48, 586-590. 
Hikita, M.; Yanagihara, M.; Nakazawa, K.; Ueno, H.; Hirose, Y.; Ueda, T.; Uemoto, Y.; Tanaka, T.; Ueda, D.; Egawa, T. $\mathrm{AlGaN} / \mathrm{GaN}$ power HFET on silicon substrate with source-via grounding (SVG) structure. IEEE Transactions on Electron Devices 2005, 52, 1963-1968.

Dora, Y.; Chakraborty, A.; McCarthy, L.; Keller, S.; DenBaars, S.; Mishra, U. High breakdown voltage achieved on $\mathrm{AlGaN} / \mathrm{GaN}$ HEMTs with integrated slant field plates. IEEE Electron Device Letters 2006, 27, 713-715.

Zhao, Z.; Du, J.; Luo, Q.; Yang, M. Impact of surface traps on the breakdown voltage of passivated AlGaN/GaN HEMTs under high-field stress. Micro \& Nano Letters 2012, 7, 1140-1142.

Guo, H.; Duan, B.; Xie, S.; Yuan, S.; Yang, Y. Enhancement-mode AlGaN/GaN HEMTs with optimised electric field using a partial GaN cap layer. Micro \& Nano Letters 2017, 12, 763-766.

Binari, S.; Dietrich, H.; Kelner, G.; Rowland, L.; Doverspike, K.; Wickenden, D. H, He, and N implant isolation of $\mathrm{n}$ - type GaN. Journal of applied physics 1995, 78, 3008-3011.

Hilt, O.; Kotara, P.; Brunner, F.; Knauer, A.; Zhytnytska, R.; Würfl, J. Improved vertical isolation for normally-off high voltage GaN-HFETs on n-SiC substrates. IEEE Transactions on Electron Devices 2013, 60, 3084-3090.

Okamoto, Y.; Ando, Y.; Hataya, K.; Nakayama, T.; Miyamoto, H.; Inoue, T.; Senda, M.; Hirata, K.; Kosaki, M.; Shibata, N. Improved power performance for a recessed-gate AlGaN-GaN heterojunction FET with a field-modulating plate. IEEE Transactions on Microwave theory and techniques 2004, 52, 2536-2540.

Wu, Y.-F.; Moore, M.; Saxler, A.; Wisleder, T.; Parikh, P. 40-W/mm double field-plated GaN HEMTs. In Proceedings of Device Research Conference, 2006 64th; pp. 151-152.

Verzellesi, G.; Morassi, L.; Meneghesso, G.; Meneghini, M.; Zanoni, E.; Pozzovivo, G.; Lavanga, S.; Detzel, T.; Haberlen, O.; Curatola, G. Influence of buffer carbon doping on pulse and AC behavior of insulated-gate field-plated power AlGaN/GaN HEMTs. IEEE Electron Device Letters 2014, 35, 443-445.

Mitani, E.; Haematsu, H.; Yokogawa, S.; Nikaido, J.; Tateno, Y. Mass production of high voltage GaAs and GaN devices. In Proceedings of CS Mantech Conference; pp. 24-27.

Mehari, S.S.; Yalon, E.; Gavrilov, A.; Mistele, D.; Bahir, G.; Eizenberg, M.; Ritter, D. Comparison of Simulation and Measurement of Gate Leakage Current in Metal/Al 2 O 3/GaN/AlGaN/AlN/GaN Capacitors. IEEE Transactions on Electron Devices 2014, 61, 3558-3561.

Huang, A.Q. Power Semiconductor Devices for Smart Grid and Renewable Energy Systems. Proceedings of the IEEE 2017, 105, 2019-2047.

Chow, T.; Ghezzo, M. SiC power devices. MRS Online Proceedings Library Archive 1996, 423.

Ozpineci, B. Comparison of wide-bandgap semiconductors for power electronics applications; ORNL: 2004.

Choi, H. Overview of silicon carbide power devices. Fairchild semiconductor 2017.

Baliga, B.J. Fundamentals of power semiconductor devices; Springer Science \& Business Media: 2010.

Jatal, W.; Baumann, U.; Tonisch, K.; Schwierz, F.; Pezoldt, J. High-frequency performance of GaN high-electron mobility transistors on 3C-SiC/Si substrates with Au-free ohmic contacts. IEEE Electron Device Letters 2015, 36, 123-125.

Wang, Z.; Zou, Z.; Zheng, Y. Design and control of a photovoltaic energy and SMES hybrid system with current-source grid inverter. IEEE Transactions on Applied Superconductivity 2013, 23, 5701505-5701505.

Geury, T.; Pinto, S.; Gyselinck, J. Current source inverter-based photovoltaic system with enhanced active filtering functionalities. IET Power Electronics 2015, 8, 2483-2491.

Ohnuma, Y.; Orikawa, K.; Itoh, J.-i. A single-phase current-source PV inverter with power decoupling capability using an active buffer. IEE E Transactions on Industry Applications 2015, 51, 531-538.

Chow, T.P. High-voltage $\mathrm{SiC}$ and GaN power devices. Microelectronic Engineering 2006, 83, 112-122.

Alves, L.F.; Gomes, R.C.; Lefranc, P.; Pegado, R.d.A.; Jeannin, P.-O.; Luciano, B.; Rocha, F.V. SIC power devices in power electronics: An overview. In Proceedings of Power Electronics Conference (COBEP), 2017 Brazilian; pp. 1-8.

Shenai, K.; Scott, R.S.; Baliga, B.J. Optimum semiconductors for high-power electronics. IEEE transactions on Electron Devices 1989, 36, 1811-1823.

Roccaforte, F.; Fiorenza, P.; Greco, G.; Vivona, M.; Nigro, R.L.; Giannazzo, F.; Patti, A.; Saggio, M. Recent advances on dielectrics technology for SiC and GaN power devices. Applied Surface Science 2014, 301, 9-18.

Dimitrijev, S.; Han, J.; Moghadam, H.A.; Aminbeidokhti, A. Power-switching applications beyond silicon: Status and future prospects of $\mathrm{SiC}$ and $\mathrm{GaN}$ devices. MRS Bulletin 2015, 40, 399-405.

Udrea, F.; Deboy, G.; Fujihira, T. Superjunction power devices, history, development, and future prospects. IEEE Transactions on Electron Devices 2017, 64, 720-734.

Jarndal, A.; Kompa, G. A new small-signal modeling approach applied to GaN devices. IEEE Transactions on Microwave Theory and Techniques 2005, 53, 3440-3448.

Medjdoub, F.; Carlin, J.-F.; Gonschorek, M.; Feltin, E.; Py, M.; Ducatteau, D.; Gaquiere, C.; Grandjean, N.; Kohn, E. Can InAlN/GaN be an alternative to high power/high temperature AlGaN/GaN devices? In Proceedings of Electron Devices Meeting, 2006. IEDM'06. International; pp. 1-4.

Wang, K.; Yang, X.; Wang, L.; Jain, P. Instability Analysis and Oscillation Suppression of Enhancement-Mode GaN Devices in Half-Bridge Circuits. IEEE Transactions on Power Electronics 2018, 33, 1585-1596.

Perkins, S.; Arvanitopoulos, A.; Gyftakis, K.; Lophitis, N. A comprehensive comparison of the static performance of commercial GaN-on-Si devices. In Proceedings of Wide Bandgap Power Devices and Applications (WiPDA), 2017 IEEE 5th Workshop on; pp. 177-184.

Liang, Z.; Ning, P.; Wang, F. Development of advanced all-SiC power modules. IEEE transactions on power electronics 2014, 29, 2289-2295.

Chen, K.J.; Häberlen, O.; Lidow, A.; lin Tsai, C.; Ueda, T.; Uemoto, Y.; Wu, Y. GaN-on-Si power technology: Devices and applications. IEEE Transactions on Electron Devices 2017, 64, 779-795.

Baliga, B.J. Gallium nitride devices for power electronic applications. Semiconductor Science and Technology 2013, 28, 074011.

Lidow, A.; Strydom, J.; De Rooij, M.; Reusch, D. GaN transistors for efficient power conversion; John Wiley \& Sons: 2014. Lidow, A.; Reusch, D. A new generation of power semiconductor packaging paves the way for higher efficiency power conversion. In Proceedings of Integrated Power Packaging (IWIPP), 2015 IEEE International Workshop on; pp. 99-102. 
Grigsby, L.L. Power system stability and control; CRC press: 2016.

Yang, Y.; Wang, H.; Sangwongwanich, A.; Blaabjerg, F. Design for reliability of power electronic systems. In Power Electronics Handbook (Fourth Edition), Elsevier: 2018; pp. 1423-1440.

Hao, R.; Xu, N.; Yu, G.; Song, L.; Chen, F.; Zhao, J.; Deng, X.; Li, X.; Cheng, K.; Fu, K. Studies on Fabrication and Reliability of GaN High-Resistivity-Cap-Layer HEMT. IEEE Transactions on Electron Devices 2018.

Strittmatter, R.; Zhou, C.; Lidow, A.; Ma, Y. Enhancement mode gallium nitride transistor reliability. In Proceedings of Applied Power Electronics Conference and Exposition (APEC), 2015 IEEE; pp. 1409-1413.

Reusch, D.; Glaser, J. DC-DC Converter Handbook: A Supplement to GaN Transistors for Efficient Power Conversion; Power Conversions Publications: 2015.

Huang, X.; Du, W.; Lee, F.C.; Li, Q.; Zhang, W. Avoiding divergent oscillation of a cascode GaN device under high-current turn-off condition. IEEE Transactions on Power Electronics 2017, 32, 593-601.

Ma, J.; Matioli, E. Slanted tri-gates for high-voltage GaN power devices. IEEE Electron Device Letters 2017, 38, 1305-1308. Meneghini, M.; Meneghesso, G.; Zanoni, E. Power GaN Devices; Springer: 2017.

Mishra, U.K.; Guidry, M. Lateral GaN Devices for Power Applications (from kHz to GHz). In Power GaN Devices, Springer: 2017; pp. 69-99.

Yu, C.; Buttay, C.; Labouré, É. Thermal management and electromagnetic analysis for GaN devices packaging on DBC substrate. IEEE Transactions on Power Electronics 2017, 32, 906-910.

Zhang, W.; Wang, F.; Costinett, D.J.; Tolbert, L.M.; Blalock, B.J. Investigation of gallium nitride devices in high-frequency LLC resonant converters. IEEE Transactions on Power Electronics 2017, 32, 571-583.

Shibata, D.; Kajitani, R.; Handa, H.; Shiozaki, N.; Ujita, S.; Ogawa, M.; Tanaka, K.; Tamura, S.; Hatsuda, T.; Ishida, M. Vertical GaN-based power devices on bulk GaN substrates for future power switching systems. In Proceedings of Gallium Nitride Materials and Devices XIII; p. 1053211.

Wang, K.; Yang, X.; Li, H.; Wang, L.; Jain, P. A High-Bandwidth Integrated Current Measurement for Detecting Switching Current of Fast GaN Devices. IEEE Transactions on Power Electronics 2018, 33, 6199-6210.

Layer, E.G. Fundamentals of Gallium Nitride Power Transistors.

Saito, W.; Nitta, T.; Kakiuchi, Y.; Saito, Y.; Tsuda, K.; Omura, I.; Yamaguchi, M. A 120-W boost converter operation using a high-voltage GaN-HEMT. IEEE Electron Device Letters 2008, 29, 8-10.

Wu, Y.; Jacob-Mitos, M.; Moore, M.L.; Heikman, S. A 97.8\% efficient GaN HEMT boost converter with 300-W output power at $1 \mathrm{MHz}$. IEEE Electron Device Letters 2008, 29, 824-826.

Chen, W.; Wong, K.-Y.; Chen, K.J. Single-chip boost converter using monolithically integrated AlGaN/GaN lateral field-effect rectifier and normally off HEMT. IEEE electron device letters 2009, 30, 430-432.

Mitova, R.; Ghosh, R.; Mhaskar, U.; Klikic, D.; Wang, M.-X.; Dentella, A. Investigations of 600-V GaN HEMT and GaN diode for power converter applications. IEEE transactions on power electronics 2014, 29, 2441-2452.

Han, D.; Morris, C.T.; Lee, W.; Sarlioglu, B. A case study on common mode electromagnetic interference characteristics of GaN HEMT and Si MOSFET power converters for EV/HEV s. IEEE Transactions on Transportation Electrification 2017, 3, 168-179.

Costinett, D.; Nguyen, H.; Zane, R.; Maksimovic, D. GaN-FET based dual active bridge DC-DC converter. In Proceedings of Applied Power Electronics Conference and Exposition (APEC), 2011 Twenty-Sixth Annual IEEE; pp. 1425-1432.

Zacharias, P.; Burger, B. Overview of recent developments for grid-connected PV systems. In Proceedings of Proc. European PV Solar Energy Conf.

Hu, H.; Harb, S.; Kutkut, N.; Batarseh, I.; Shen, Z.J. Power decoupling techniques for micro-inverters in PV systems-a review. In Proceedings of Energy Conversion Congress and Exposition (ECCE), 2010 IEEE; pp. 3235-3240.

Khanh, L.N.; Seo, J.-J.; Kim, Y.-S.; Won, D.-J. Power-management strategies for a grid-connected PV-FC hybrid system. IEEE transactions on power delivery 2010, 25, 1874-1882.

Katiraei, F.; Aguero, J.R. Solar PV integration challenges. IEEE Power and Energy Magazine 2011, 9, 62-71.

Jakhrani, A.Q.; Rigit, A.R.H.; Othman, A.K.; Samo, S.R.; Kamboh, S.A. Life cycle cost analysis of a standalone PV system. In Proceedings of Green and Ubiquitous Technology (GUT), 2012 International Conference on, 7-8 July 2012; pp. 82-85.

Cristian, H.I.; Raducu, M. Energy efficiency analysis of various topologies, control techniques and technologies used for photovoltaic panels Part I: On thePV modeling and problem of extracting the maximum power. In Proceedings of Electronics, Computers and Artificial Intelligence (ECAI), 2014 6th International Conference on, 23-25 Oct. 2014; pp. 23-28.

Fernandes, F.T.; Farret, F.A.; Longo, A.J.; Nardin, C.R.d.; Trapp, J.G. PV efficiency improvement by underground heat exchanging and heat storage. In Proceedings of Renewable Power Generation Conference (RPG 2014), 3rd, 24-25 Sept. 2014; pp. 1-6.

Potdukhe, K.C.; Munshi, A.P.; Munshi, A.A. Reliability analysis of Voltage source inverter and Current source inverter for solar PV System. In Proceedings of 2015 International Conference on Electrical, Electronics, Signals, Communication and Optimization (EESCO), 24-25 Jan. 2015; pp. 1-5.

Singaravel, M.R.; Daniel, S.A. MPPT with single DC-DC converter and inverter for grid-connected hybrid wind-driven PMSGPV system. IEEE Transactions on Industrial Electronics 2015, 62, 4849-4857.

Agarwal, N.; Arya, A.; Ahmad, M.W.; Anand, S. Lifetime Monitoring of Electrolytic Capacitor to Maximize Earnings From Grid-Feeding PV System. IEEE Transactions on Industrial Electronics 2016, 63, 7049-7058, doi:10.1109/TIE.2016.2586020. Kouro, S.; Leon, J.I.; Vinnikov, D.; Franquelo, L.G. Grid-connected photovoltaic systems: An overview of recent research and emerging PV converter technology. IEEE Industrial Electronics Magazine 2015, 9, 47-61.

Zhang, H.; Ge, B.; Liu, Y.; Bayhan, S.; Balog, R.S.; Abu-Rub, H. Comparison of GaN and SiC power devices in application to MW-scale quasi-Z-source cascaded multilevel inverters. In Proceedings of Energy Conversion Congress and Exposition (ECCE), 2016 IEEE; pp. 1-7.

Acanski, M.; Popovic-Gerber, J.; Ferreira, J. Comparison of Si and GaN power devices used in PV module integrated converters. In Proceedings of Energy Conversion Congress and Exposition (ECCE), 2011 IEEE; pp. 1217-1223.

Nonaka, S. A suitable single-phase PWM current source inverter for utility interactive photovoltaic generation system. IEEJ Transactions on Industry Applications 1994, 114, 631-637. 
86. Ouchi, T.; Fujikawa, H.; Masukawa, S.; Iida, S. A control scheme for a three - phase current source inverter in utility interactive photovoltaic system. Electrical Engineering in Japan 2001, 135, 43-55.

87. Barbosa, P.G.; Braga, H.A.C.; Rodrigues, M.d.C.B.; Teixeira, E.C. Boost current multilevel inverter and its application on single-phase grid-connected photovoltaic systems. IEEE transactions on power electronics 2006, 21, 1116-1124.

88. Klumpner, C. A new single-stage current source inverter for photovoltaic and fuel cell applications using reverse blocking IGBTs. In Proceedings of Power Electronics Specialists Conference, 2007. PESC 2007. IEEE; pp. 1683-1689.

89. Kyritsis, A.C.; Tatakis, E.; Papanikolaou, N. Optimum design of the current-source flyback inverter for decentralized gridconnected photovoltaic systems. IEEE Transactions on Energy Conversion 2008, 23, 281-293.

90. Sahan, B.; Vergara, A.N.; Henze, N.; Engler, A.; Zacharias, P. A single-stage PV module integrated converter based on a lowpower current-source inverter. IEEE Transactions on Industrial Electronics 2008, 55, 2602-2609.

91. Román, I.T.; Silva, L.S. A single-phase current-source inverter with active power filter for grid-tied PV systems. In Proceedings of Power Electronics for Distributed Generation Systems (PEDG), 2012 3rd IEEE International Symposium on; pp. 349-356.

92. Ohnuma, Y.; Orikawa, K.; Itoh, J.i. A single-phase current source PV inverter with power decoupling capability using an active buffer. In Proceedings of 2013 IEEE Energy Conversion Congress and Exposition, 15-19 Sept. 2013; pp. 3094-3101. 